\title{
In vitro Wear of Aged Composite Restorative Materials
}

\author{
P. L. FAN and J. M. POWERS
}

School of Dentistry, University of Michigan, Ann Arbor, Michigan 48109

Wear characteristics of aged and unaged composite restorative materials were compared using singlepass sliding. There were differences in wear track widths, tangential forces, and surface failure classifications between aged and unaged composites. Changes in surface wear characteristics upon aging were attributed to surface degradation in the composite materials.

J Dent Res 59(12):2066-2070, December 1980

\section{Introduction.}

Wear of restorative materials has been characterized in vitro using single-pass sliding. ${ }^{4}$ Wear patterns and surface structures of composite restorations in vivo have been reported by Kusy and Leinfelder 5 and by $O^{\prime} B r i e n$ and Yee. 6 However, there have been few reports on the correlation between in vitro and in vivo wear. One reason could be that the in vivo wear characteristics result from gradual changes in the properties of the composite restorative materials in the oral environment. Accelerated aging of composites in vitro has been shown to cause erosion accompanied by changes in surface profiles and exposure of filler particles. ${ }^{7}$ The present study characterizes the in vitro wear of composite restorative materials by single-pass sliding after accelerated aging and compares the wear characteristics with those of unaged composite restorative materials.

\section{Materials and methods.}

Six chemically-cured composites (A,

Received for publication January 21, 1980 Accepted for publication May 8, 1980

This investigation was presented at the annual meeting of the American Association for Dental Research in Los Angeles, CA, March, 1980.

This investigation was supported by USPHS Grant No. DE-03416 from the National Institute of Dental Research, National Institutes of Health, Bethesda, MD 20205.
AR, C, PR, S, and V), two ultraviolet lightcured composites (NF and NFPA), and three chemically-cured microfilled composites (PF, SF, and SI) were used in this study. Product names, codes, batch numbers, and manufacturers are shown in Table 1.

Each chemically-cured composite was mixed according to the manufacturer's instructions and packed into a stainless steel ring mold $36 \mathrm{~mm}$ in diameter and 1.3 $\mathrm{mm}$ thick. The surfaces were covered with Mylar* and allowed to cure for seven min. The ultraviolet light-cured composite samples were prepared by packing the material into the mold, covering with Mylar, and then exposing one side of the sample to an ultraviolet light source ${ }^{\dagger}$ for two min at a distance of $50 \mathrm{~mm}$.

The sample disks were exposed to accelerated aging conditions for $900 \mathrm{~h}$ in a weathering chambert at $43^{\circ} \mathrm{C}$ and $90 \%$ humidity. One surface of each sample was continuously irradiated by a 2500 watt xenon light source, $\S$ which was filtered by borosilicate glass giving an ultraviolet radiation intensity of $112 \mu \mathrm{watt} / \mathrm{mm}^{2}$ at the sample position. An intermittent water spray was directed at the samples for $18 \mathrm{~min}$ every $120 \mathrm{~min}$. Samples used as controls were not subjected to accelerated aging, but were tested after 24 hours' storage in $37^{\circ} \mathrm{C}$ distilled water.

Single-pass sliding experiments on the samples were performed on an apparatus described in detail by Powers and Craig. 8,9 Four replications were used for each material. Surfaces of the composites were sub\footnotetext{
19132

*Moyco Industries, Inc., Philadelphia, PA

†lak-Ray, B-110 A, Ultra-Violet Products, Inc., San Gabriel, CA 91775

Weather-Ometer 25 WR, Atlas Electric Devices, Inc., Chicago, IL 60613

$\$ 12-2881$ Xenon Burner, Atlas Electric Devices, Inc., Chicago, IL 60613
} 
TABLE 1

CODE, PRODUCT NAME, BATCH NUMBER, AND MANUFACTURER OF MATERIALS EVALUATED

\begin{tabular}{lllll}
\hline Code & Product & \multicolumn{2}{c}{ Batch Number } & \multicolumn{1}{c}{ Manufacturer } \\
\hline A & Adaptic & Universal & $8 \mathrm{C} 004$ & Johnson and Johnson Dental Products \\
& & Catalyst & $8 \mathrm{C} 004$ & East Windsor, NJ 08520 \\
AR & Adaptic & Universal & $8 \mathrm{H} 109$ & Johnson and Johnson Dental Products \\
& Radiopaque & Catalyst & $8 \mathrm{H} 109$ & \\
$\mathrm{C}$ & Concise & Universal & $8 \mathrm{Y} 21$ & 3M Company \\
& & Catalyst & & St. Paul, MN 55101 \\
NF & Nuva-Fil & Base & 7426 & L. D. Caulk Company \\
& & Initiator & 7661 & Milford, DE 19963 \\
NFPA & Nuva-Fil P.A. & & 661278 & L. D. Caulk Company \\
PF & Phaseafill & Base & 026 & Phasealloy, Inc. \\
& & Catalyst & 044 & El Cajon, CA 92021 \\
PR & Profile & Universal & 48712 & S. S. White Dental Products \\
& & Catalyst & 37901 & International \\
& & & & Philadelphia, PA 19102 \\
S & Simulate & Universal & $77-22-16$ & Kerr Manufacturing Co. \\
& & Catalyst & $77-12-13$ & Romulus, MI 48174 \\
SF & Superfil & Universal & 80338 & Harry J. Bosworth Company, \\
& & Catalyst & 80329 & Skokie, IL 60076 \\
SI & Silar & Paste A MPP & $501-37$ & 3M Company \\
& & Paste B MPP & $397-37$ & \\
V & Vytol & Universal & 041278 & L. D. Caulk Company \\
& & Catalyst & 041478 & \\
& & & &
\end{tabular}

jected to the sliding of a diamond hemisphere (360 $\mu \mathrm{m}$ diameter) at a sliding speed of $0.25 \mathrm{~mm} / \mathrm{sec}$. The normal loads ranged from 1 to $10 \mathrm{~N}$ in increments of $1 \mathrm{~N}$. Tangential forces were recorded using a strain gauge transducer. The wear track widths were measured using a calibrated eyepiece in a metallurgical microscope. Optical microscopy and scanning electron microscopy were used to examine the surface failure modes. Classifications of the failure modes were: ductile, Class 1 ; tensile cracking, Class 3 ; and extensive chevron formation, Class 5. Classes 2 and 4 are intermediate classifications and represent mixtures of the above-mentioned failure modes. ${ }^{10}$ Classes 4 and 5 involve distinct loss of materials.

\section{Results.}

Figs. 1 through 5 show the average wear track widths and tangential forces at various normal loads for aged and unaged $\mathrm{C}, \mathrm{NF}, \mathrm{PF}$, $S I$, and SF, respectively. Aged and unaged $A, A R, P R, S$, and $V$ were similar to $C$, although the magnitudes were different for each composite. NFPA was similar to NF.

Classification of the surface failure modes at various normal loads for the aged

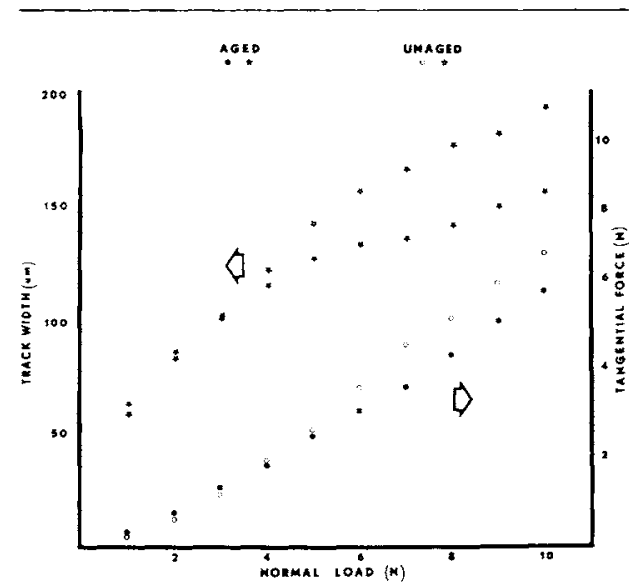

Fig. 1 - Wear track widths and tangential forces for aged and unaged composite $C$. 


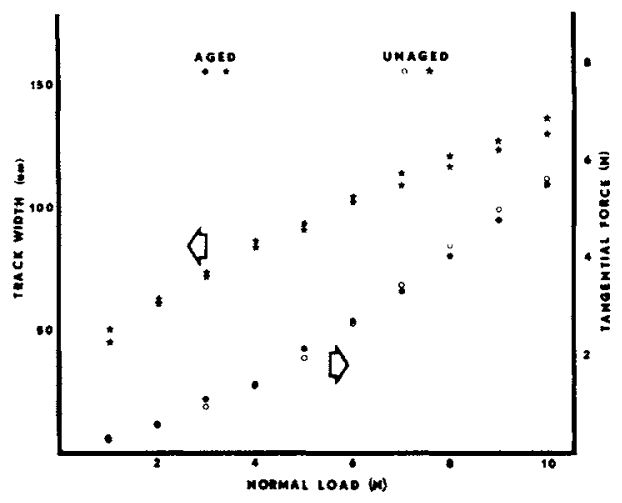

Fig. 2 - Wear track widths and tangential forces for aged and unaged composite NF.

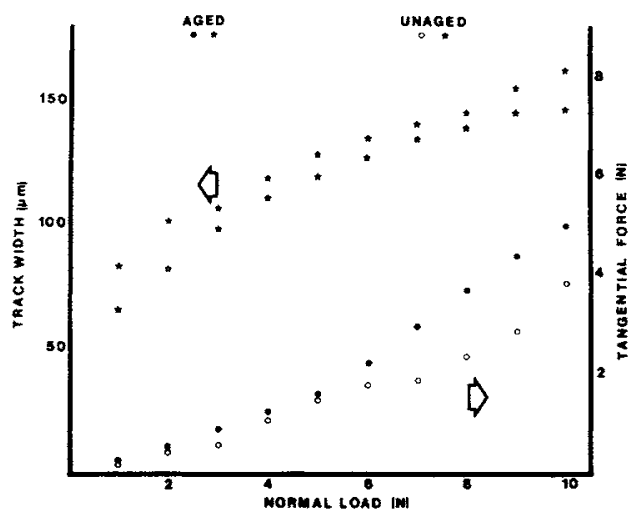

Fig. 3 - Wear track widths and tangential forces for aged and unaged composite PF.

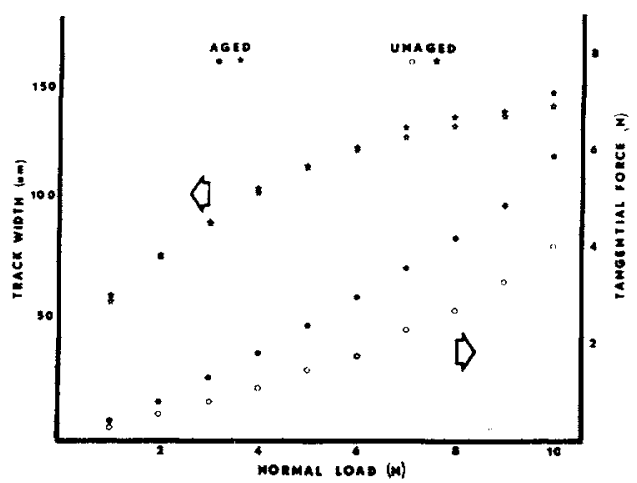

Fig. 4 - Wear track widths and tangential forces for aged and unaged composite SI.

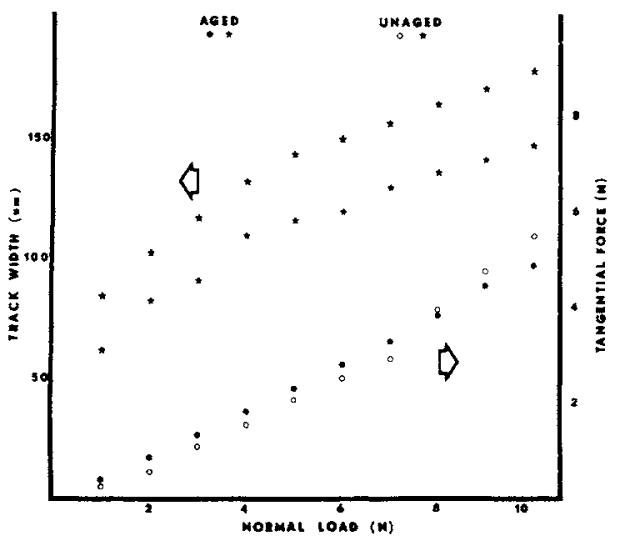

Fig. 5 - Wear track widths and tangential forces for aged and unaged composite SF.

and unaged composites are shown in Table 2. Scanning electron micrographs of wear tracks on aged and unaged composites at a normal load of $6 \mathrm{~N}$ are shown in Fig. 6 .

There were differences in wear characteristics between aged and unaged samples of the chemically-cured composites (A, $A R, C, P R, S$, and $V$ ). The aged samples had lower wear track widths and lower tangential forces for normal loads of $5 \mathrm{~N}$ to $10 \mathrm{~N}$. Aged composites reached a Class 4 surface failure mode with loss of material at lower normal loads than unaged composites and showed less loss of material during single-pass sliding at higher normal loads.

The ultraviolet light-cured composites (NF and NFPA) showed little difference between aged and unaged samples in wear track widths and tangential forces. There were differences in modes of surface failure between aged and unaged samples. A small amount of dislodging of materials along the wear tracks was observed at normal loads of 2-3 $\mathrm{N}$ for the aged samples, whereas ductile failure (Class 1) was evident in the unaged samples under similar normal loads.

There were differences in wear characteristics between aged and unaged samples of microfilled composites and among the microfilled composites themselves. Aged PF showed wider wear tracks and higher tangential forces than unaged PF. Composite SI showed little difference in wear track widths between aged and unaged samples. The tangential forces were higher for the aged samples than for the unaged samples at similar normal loads. Aged SI showed Class 
TABLE 2

SURFACE FAILURE CLASSIFICATIONS OF COMPOSITES

\begin{tabular}{lrcc}
\hline \hline & \multicolumn{3}{c}{ Load (N) at Which Failure } \\
Occurred & Class 3 & Class 4 \\
\hline A & Class 1 & - & $3-10$ \\
A aged & $1-2$ & - & $2-10$ \\
AR & 1 & - & $3-10$ \\
AR aged & $1-2$ & - & $2-10$ \\
C & 1 & - & $3-10$ \\
C aged & $1-2$ & - & $2-10$ \\
NF & 1 & - & $4-10$ \\
NF aged & $1-3$ & - & $2-10$ \\
NFPA & 1 & - & $4-10$ \\
NFPA aged & $1-3$ & - & $2-10$ \\
PF & 1 & - & 10 \\
PF aged & $1-9$ & - & $6-10$ \\
PR & $1-5$ & - & $5-10$ \\
PR aged & $1-4$ & - & $3-10$ \\
S & $1-2$ & - & $2-10$ \\
S aged & $1-2$ & -10 & - \\
SF & 1 & - & $6-10$ \\
SF aged & $1-5$ & - & $9-10$ \\
SI & $1-5$ & - & $2-10$ \\
SI aged & $1-8$ & -10 \\
V & $1-2$ & -10 \\
V aged & 1 & & \\
\hline & 1 & - &
\end{tabular}

4 failure modes at lower normal loads than unaged samples. Composite SF had lower wear track widths in aged than unaged samples. There was little difference in tangential force for aged and unaged SF at similar normal loads. Unaged PF showed Class 1 surface failure mode up to normal loads of $9 \mathrm{~N}$, while aged PF reached Class 4 surface failure mode at a normal load of $6 \mathrm{~N}$ and was accompanied by dislodging of material. At normal loads of 6 to $10 \mathrm{~N}$, unaged SF showed Class 3 surface failure with tensile cracking, while aged SF showed Class 4 surface failure with dislodging of material, but fewer tensile cracks.

\section{Discussion.}

Accelerated aging of composite samples has been shown to result in surface degradation and eventual erosion. ${ }^{7}$ Exposure of the samples to the accelerated aging conditions causes degradation in the chemical structure

\section{UNAGED AGED}

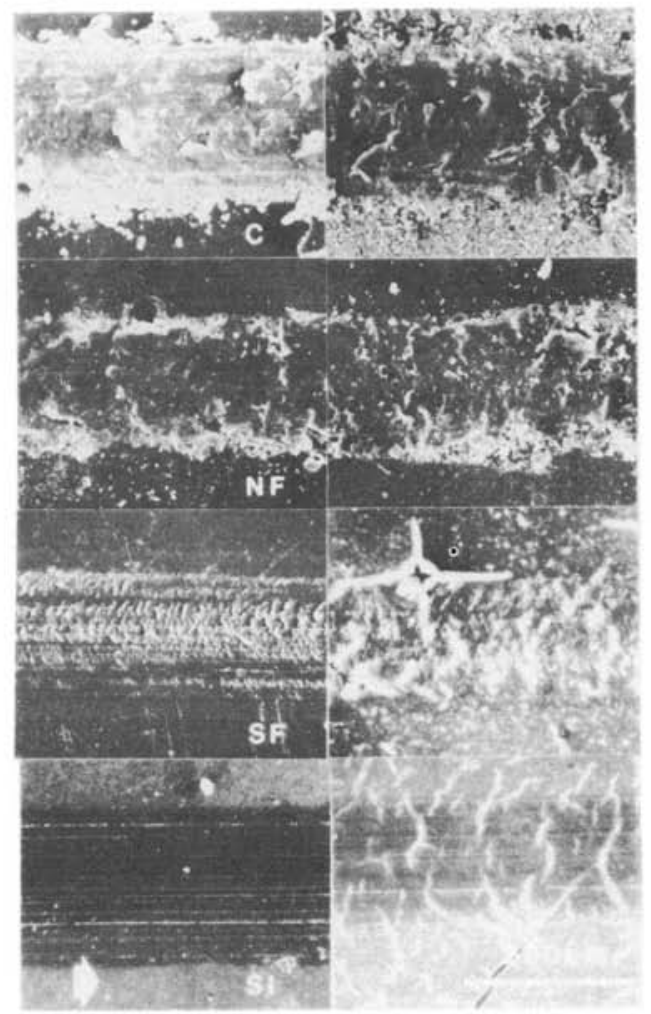

Fig. 6 - Scanning electron micrographs of wear tracks at $6 \mathrm{~N}$ normal load. Arrow indicates direction of sliding.

within the components of the composite materials and the interfacial bonds between the resin matrices and the filler particles. Surface degradation is accompanied by increases in surface imperfections, crazing, and decrease in cohesion in the composite materials. This degradation reduces the extent of surface failure propagation and also makes dislodging of material easier. The affected area in single-pass sliding can be considered as a zone of influence. Within this zone, the composite material is under the stress of the moving diamond slider, and certain modes of surface failure result. Decreases in cohesion caused by surface degradation reduce the magnitude of this zone of influence and modify the extent of surface failure under similar applied normal loads. A decrease in cohesion in aged composites, therefore, results in smaller track 
widths, lower tangential forces, easier dislodging of material, and more severe surface failure at lower normal loads than unaged composites. This explanation applies to the chemically-cured conventional composites.

The extent of surface degradation was considerably less for the two ultraviolet light-cured composites under these accelerated aging conditions. This reduced degradation may have resulted from differences in compositions and curing conditions when compared with the chemicallycured conventional composites.

The effect of accelerated aging on the wear characteristics of microfilled composites was more complex. As unaged microfilled composites showed wear characteristics different from one another and from the conventional composites, ${ }^{4}$ surface degradation of microfilled composites resulted in different changes in wear track widths, tangential forces, and surface failure morphologies for each material. Loss of material, however, occurred at lower normal loads for all microfilled composites, showing easier removal of aged composite materials as a result of surface degradation.

Composite restorations are subjected to aging in the oral environment, although the aging conditions are not identical to the in vitro aging used in this investigation. However, a slow rate of surface degradation of plastics and composites does exist. Breaking of chemical bonds in the composite material can result by heat, hydrolysis, and other chemical cleavage conditions, instead of by means of ultraviolet radiation. The degraded surface layer is more easily removed by abrasion and erosion, exposing new surfaces susceptible to degradation. The aging and surface degradation of composite restorative materials may affect their performances in vivo.

\section{Conclusions.}

In vitro wear characteristics of composite restorative materials exposed to accelerated aging conditions differed from those of the unaged materials. The changes in wear track widths, tangential forces, surface failure classification, and surface failure morphologies were attributed to surface degradation in the composites on aging.

\section{REFERENCES}

1. POWERS, J.M.; ROBERTS, J.C.; and CRAIG, R.G.: Surface Failure of Commercial and Experimental Restorative Resins, $J$ Dent Res $55: 432-436,1976$.

2. ROBERTS, J.C.; POWERS, J.M.; and CRAIG, R.G.: Wear of Dental Amalgam, $J$ Biomed Mater Res 11:513-523, 1977.

3. ROBERTS, J.C.; POWERS, J.M.; and CRAIG, R.G.: Wear of Commercial Pit and Fissure Sealants, J Dent Res 56:692, 1977.

4. FAN, P.L.; POWERS, J.M.; and CRAIG, R.G.: In vitro Wear of Microfilled and Visible Light-cured Composites, J Dent Res 58: 2116-2119, 1979.

5. KUSY, R.P. and LEINFELDER, K.F.: Pattern of Wear in Posterior Composite Restorations, J Dent Res 56:544, 1977.

6. O'BRIEN, W.J. and YEE, J., Jr.: Surface Structure of Class II Composite Restorations After Clinical Wear, IADR Progr \& Abst 58: No. 942, 1979.

7. POWERS, J.M. and FAN, P.L.: Erosion of Composite Resins, J Dent Res 59:815-819, 1980.

8. POWERS, J.M. and CRAIG, R.G.: Wear of Fluorapatite Single Crystals: I. A Method for Quantitative Evaluation of Wear, $J$ Dent Res 51:168-176, 1972.

9. POWERS, J.M. and CRAIG, R.G.: Wear of Fluorapatite Single Crystals: II. Frictional Behavior, $J$ Dent Res 51:605-610, 1972.

10. POWERS, J.M. and CRAIG, R.G.: Wear of Fluorapatite Single Crystals: III. Classification of Surface Failure, $J$ Dent Res 51:611-618, 1972. 